\title{
A Performance Solo como engrenagens de Memórias e Coletividades
}

Renato Ferracini

Seria demasiado simplista relacionar a alta produção de solos (também chamados monólogos) somente à questão da falta de verbas, dificuldades financeiras ou ainda a uma negação ao conceito de companhias. Um primeiro perigo em afirmar essa relação causa-efeito demasiado rigorosa é gerar um pano de fundo no qual os solos são tratados como uma produção menor. Ora, já que não temos verba para criar um espetáculo grande e de impacto, já que não temos suporte para realizar uma produção relevante, façamos um simples solo! Ou ainda: já que não conseguimos ter uma companhia e conviver em grupo para realizar produções espetaculares de alto teor ideológico e estético, façamos um simples solo! O contraponto disso é óbvio: se os solos podem ser considerados uma produção menor, ou gerados somente em relação a uma falta de verba ou ao esvaziamento da produção de companhias, estabelecemos uma hierarquia de produtividade: as grandes produções fomentadas e patrocinadas e/ou os espetáculos de grupos consagrados seriam considerados os espetáculo "sérios", efetivos, relevantes esteticamente enquanto os solos seriam somente frutos de uma crise financeira, estética e do modo de produção espetacular. Essa visão tacanha sobre uma produção relevante como os solos oblitera um pensamento mais verticalizado sobre suas funções estéticas, sociológicas, antropológicas e ontológicas. Diminui a possibilidade de pensarmos o solo como um tipo de produção específica, em nada inferior ou situada num território menor. Não quero afirmar com isso que todo solo, somente por ser solo, já possui uma relevância estética. Mas da mesma forma, seria impossível predizer que um espetáculo gerado por uma grande companhia fomentada garante sua qualidade de produção.

Essa hierarquização moral e preconceituosa da produção teatral, por si mesma, já seria motivo de crítica e questionamento. Além disso, podemos verificar que os argumentos 
que suportam esse pensamento perdem força em sua própria base já que ao realizarmos um breve sobrevoo em exemplos de fomento e produção de companhias e coletivos essa suposta crise das companhias não está tão clara. Citarei dois exemplos:

1) Na cidade de São Paulo verificamos que não há, em realidade, uma crise ou esvaziamento da produção das companhias: a Lei de Fomento do Município dá prioridade para o fomento à grupos longevos, estabelecidos e de pesquisa o que estimula a produção de espetáculos das companhias formadas bem como a estimula a geração de novos coletivos.

2) Em nível federal temos o Programa Petrobras Cultural com editais específicos de circulação e processos criativos direcionados a companhias estabelecidas de teatro.

Enfim, os exemplos poderiam ser muitos, mas me aterei apenas a esses dois. Portanto, as companhias brasileiras de teatro e dança reconhecidas nacional e internacionalmente seguem com produções de fôlego e vão muito bem obrigado! Paralelamente, a produção de solos não somente acontece de forma potente como parece crescer a cada ano. Então, por que isso ocorre?

Uma primeira resposta passa pela questão de experimentação estética que atravessa o conceito de composição. Todo espetáculo, seja solo ou gerado em uma companhia, passa pela capacidade de composição com o público, e é nesse ato de compor poeticamente que a encenação e o ator garantem uma certa qualidade estética em seu fazer. Em outras palavras: todo espetáculo, mesmo se gerado somente por um ator ou atriz, deveria ser capaz de realizar uma composição estética coletiva dos corpos em presença. Ao contrário do que comumente se pensa, o ator ou a atriz (que chamarei a partir de agora de atuante) não deveria somente impor a presença de seu corpo e sua técnica para o público. A presença de um atuante não é algo que possa ser localizado em sua massa muscular na presença ou ausência dos signos que esse corpo produz, na capacidade de reter uma determinada atenção do espectador ou ainda na imaginação ou capacidade semiótica dos espectadores. A presença do atuante está na relação dinâmica "entre" todos esses espaços, elementos e zonas. A presença não é produção ou atributo de um elemento cênico ou corpóreo, mas (in)produção, diluição, capacidade que esse corpo possui em se lançar, ele mesmo e os espectadores, em zonas de contágio, contaminação e turbulência. Falar de contágio e de contaminação é o mesmo que dizer de uma certa capacidade do atuante de se abrir em receptividade para o afeto do outro (uma certa escuta) e ao mesmo tempo produzir com esse afeto uma ação que afeta. Contaminação, contágio, um estado de peste é a competência, portanto, de afetar e ser afetado, uma "escuta-ação", ou simplesmente "escutação". O atuante, em seu ofício, deveria fazer 
sempre a mesma pergunta dinâmica: Como compor afetivamente (capacidade de afetar e ser afetado) esse plano de forças poéticas que nos atravessam e essas partes extensivas que nos formam na cena e ao mesmo tempo diluir-se nessa zona, dissolvendo também aí a técnica, o ego, a imposição da vontade? Como dinamizar essa escutação?

Aqui entra a zona privilegiada do espetáculo solo, pois o atuante tem nesse território a capacidade de buscar produzir sozinho essa zona de contágio. Falo, portanto, do espetáculo solo como espaço de experimentação plena para o atuante. É nele que se pode observar, para além da busca do experimento único e específico e da procura da autonomia da expressão, todo um campo de experiência no qual o atuante pode coletivizar uma singularidade. A pergunta de como ir da experiência única e autônoma de criação para uma zona estética de contaminação coletiva é a grande potência estética que o solo proporciona.

Arrisco dizer que essa questão, inclusive, é fundamental para companhias de teatro. No LUME, os solos são momentos de respiro de criação e experiências estéticas únicas para os atores. Cada ator do LUME deve aprender a ser um coletivo mesmo em sua singularidade e o solo, comojá disse, é um espaço excepcional para esse "teste" estético. Cada ator do LUME deve treinar a capacidade de composição e, portanto, de contaminação. E qual lugar mais perigoso e solitário que um espetáculo solo para colocar essa questão em sua liminaridade? É assim que o LUME vê o solo: um lugar de experiências de limite no qual a positividade paradoxal singular/coletivo deve estar em plena discussão cênica. E aqui apresento ainda outro paradoxo: no LUME são os espetáculos solos que proporcionam a possibilidade de convivermos e criarmos coletivamente. Acreditamos que estar em grupo é ser singular e plural, homogêneo e heterogêneo ao mesmo tempo. É viver essa postura crítica de trabalho estético no cotidiano e no extracotidiano, na sala do escritório e na sala de trabalho. Viver e criar em grupo é saber e assumir sem medo que, enquanto no plano artístico buscamos uma desarticulação e um redimensionamento de nossos corpos e da obra teatral, no plano cotidiano percebemos que nossas relações internas podem ser agenciadas, articuladas, programadas, viciadas, artificializadas pela nossa história pessoal, social e do próprio grupo. Contradição inerente e intrínseca. Estar em grupo é agregar matilhas em uma grande matilha, com todas suas contradições e multiplicidades. Matilha de homens-lobo - cada qual, em si mesmo, matilhas - que possuem em comum somente correr na mesma direção assumindo as próprias diferenças e tentando, cada matilha, afetar e se deixar afetar por essas mesmas multiplicidades outras, renovando e recompondo a grande matilha. Viver em grupo é viver uma 
aspiração de trabalho, mesmo que seja virtual, e se pautar nela como ponto aglutinador. Viver em grupo é criar uma microssociedade, com suas próprias leis, jargões e até mesmo língua. Uma língua dentro da língua. No grupo podemos buscar gerar o espaço, criar os meios, cavar um território para nossos desejos e aspirações. E se for necessário ir além: gerar o espaço do espaço, a fenda da fenda, o território do território até o limite no qual seja possível respirar. Um território no qual essas aspirações e desejos possam ter, senão um "livre curso", mas ao menos a possibilidade de existência. E quando digo desejo, não o digo como uma substância que preenche um espaço de falta, um espaço vazio causado por uma maquinaria social que gera buracos artificiais de consumo que são preenchidos com a satisfação de desejos numa eterna relação de busca de prazer. Não digo desejo como preenchimento de uma falta, um buraco construído artificialmente, gerando um regozijo de desejo também artificial. Não. Quando digo desejo falo de um desejo de fugas desses desejos que suprem faltas. Falo de um desejo que, antes de suprir uma falta, nos impulsiona para a construção ou reconstrução de novas possibilidades de existência, através de um corpo-em-arte. Nesse sentido, viver em grupo, em microgrupos - que possuem microaspirações singulares, moleculares, mas que são, em si, pequenas linhas de fuga das forças estratificadas e das relações de poder que constituem as relações do socius é - bem ao contrário de uma suposta alienação - a geração de focos de resistência, a fundação de espaços para desejos singulares. Criar territórios de desejo e linhas de fuga não é, de forma alguma, "fugir" do socius, mas imprimir em sua própria estrutura pequenos pontos de possibilidade de reorganização, de devir e mudança para todos os microelementos que esse grupo propõe em suas aspirações. É dentro desse território grupal gerado, criado, forçado, pressionado que se busca uma revolução do único dentro de uma busca de reconfiguração artístico-teatral como uma reterritorialização; a arte cênica como um corpo nômade que gera seu espaço, cria seu próprio território através e dentro de sua própria desterritorialização. E apesar da certeza dessa vontade de criar fendas e espaços para possibilidades de realização de nossos desejos, tanto individuais como de grupo, existe sobre essa fresta, ao lado dela e através dela muitas e muitas dúvidas, medos, incertezas, tristezas, decepções, inseguranças e muitos erros. Se opções iniciais nos respondem aspirações e desejos imediatos, possibilitando aberturas desses espaços como possibilidade de criação e de pontos de resistência, permitindo oxigenar nossas inquietações, esses mesmos espaços geram, em si e através de si mesmos, estratificações e relações de poder que, rearticuladas nesse novo espaço mostram seus dentes com forças renovadas. E, assim, novos 
micropontos de fuga devem ser encontrados. Nesse sentido, viver em microgrupos, nessas fendas e espaços criados de desejo e resistência, também é realizar um eterno exercício de readaptação e de renovação de opções. O que faz, hoje, grupos estarem ainda juntos depois de tantos anos é a consciência da necessidade dessa eterna renovação e da re-opção. Esses grupos, vistos como espaços de possibilidade de desejo não são, absolutamente, espaços confortáveis de convivência. Muito pelo contrário, são espaços em que, ao lado de pequenas conquistas, grandes tristezas, medos, erros e decepções ocorrem e ocorrerão, e que a continuidade de existência do grupo terá de ser reconfigurada em todos os seus ciclos e nada garantirá sua existência eterna. Paradoxalmente, sabemos que quanto mais essa força de criação grupal crescer, maior será o risco de sucumbirmos ao próprio microssistema grupal criado. Uma das poucas possibilidades de sobrevivência dos grupos cênicos contemporâneos é ter consciência mínima disso. E qualquer semelhança com as relações sociais atuais não é, definitivamente, mera coincidência.

Os espetáculos solos do LUME são as engrenagens que re-colocam e re-afirmam os desejos singulares de cada atuante dentro desse todo grupal complexo. É um teste liminar que busca reafirmar seu corpo como coletivo e zona de peste. Depois de um solo o atuante do LUME reafirma sua coletividade e seu lugar dentro do coletivo. O coletivo LUME somente existe, portanto, em função das singularidades experimentais de seus espetáculos solos. Ao menos no LUME, a fórmula Solo = Coletivo, mais que uma verdade matemática, potencializa um conjunto de práticas fundamental para o pensamento estético e ético de um estar em grupo. 